\title{
Evaluation of the effect of indigenous mycogenic silver nanoparticles on soil exo-enzymes in barite mine contaminated soils
}

\author{
Durga Prameela Gaddam • Nagalakshmi Devamma • \\ Tollamadugu Naga Venkata Krishna Vara Prasad
}

Received: 2 July 2014/Accepted: 18 July 2014/Published online: 5 August 2014

(C) The Author(s) 2014. This article is published with open access at Springerlink.com

\begin{abstract}
The biosynthesis of nanoparticles has received increasing attention due to the growing need to develop safe, cost-effective and environmentally friendly technologies for nanoscale materials synthesis. In this report, silver nanoparticles (AgNPs) were synthesized by treating aqueous $\mathrm{Ag}^{+}$ions with the culture supernatants of indigenous fungal species of Fusarium solani isolated from barite mine contaminated soils. The formation of AgNPs might be an enzyme-mediated extracellular reaction process. The localized surface plasmon resonance of the formed AgNPs was recorded using UV-VIS spectrophotometer and was characterized using the techniques transmission electron microscopy, particle size analyzer, Fourier transform-infrared spectroscopy (FT-IR), particle size (dynamic light scattering) and zeta potential. The synthesized AgNPs were stable, polydispersed with the average size of $80 \mathrm{~nm}$. FT-IR spectra reveals that proteins and carboxylic groups present in the fungal secrets might be responsible for the reduction and stabilization of the silver ions. Applied to the barite mine contaminated soils, concentration of AgNPs and incubation period significantly influences the soil exo-enzymatic activities, viz., urease, phosphatase, dehydrogenase and $\beta$-glucosidase. To the best of our knowledge, this is the first report on this kind of work in barite mine contaminated soils.
\end{abstract}

D. P. Gaddam · N. Devamma ( $\square)$

Department of Botany, S.V. University, Tirupati,

A.P. 517 502, India

e-mail: devi.bot@gmail.com

T. N. V. K. V. Prasad ( $\bowtie)$

Nanotechnology Laboratory, Institute of Frontier Technology,

Regional Agricultural Research Station, Acharya N G Ranga

Agricultural University, Tirupati, A.P. 517 502, India

e-mail: tnvkvprasad@gmail.com
Keywords Silver nanoparticles $\cdot$ Fusarium solani . Biosynthesis · Soil exo-enzymes · Barite mine

\section{Introduction}

Nanotechnology includes the synthesis of nanoscale materials for versatile applications. The unique properties of nanomaterials differ substantially from bulk materialsin fact, at this scale (1-100 nm), matter behaves differently from their bulk counter parts and exhibit novel properties. Nanoparticles (NPs) are the best known nanomaterials. They have predominant surface effects for the high proportion of the atoms located on their surface that leads to a relevant increase in their reactivity. The biological behavior of NPs is determined by the chemical composition, including coatings on the surface, the decrease in size and associated increase in surface to volume ratio and the shape. In addition, aggregations of NPs may have an effect on their biological behavior as well. Many microorganisms, plant extracts and fungi have been shown to produce NPs through biological pathways (Abou ElNour et al. 2010; Mohanpuria et al. 2008; Ghorbani et al. 2011; Popescu et al. 2010; Dhoondia and Chakraborty 2012; Sastry et al. 2003; Prasad and Elumalai 2011). The use of fungi in the synthesis of metallic NPs is relatively exciting, and was identified as one of the potential microorganisms as they secrete significant amounts of enzymes that are easily handled at the laboratory level. Synthesis of silver NPs (AgNPs) has been investigated utilizing many ubiquitous fungal species including Trichoderma, Fusarium and Penicillium (Vahabi et al. 2011; Durán et al. 2005; Naveen et al. 2010). Recent research regarding the use of fungi has generally investigated potential redox systems

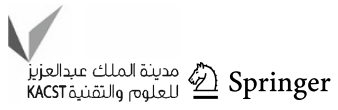


using silver nitrate as the source of silver ions (Vahabi et al. 2011; Naveen et al. 2010). Several enzymes, $\alpha$ NADPH-dependent reductases and nitrate-dependent reductases, were implicated in AgNPs synthesis from Fusarium oxysporum (Mohanpuria et al. 2008; Durán et al. 2005). Nitrate reductase was also suggested to initiate NPs formation USING in a Penicillium species (Naveen et al. 2010). Soil fungi are known to tolerate heavy metals (Baldrian 2003; Tuomela et al. 2005), but the sensitivity of fungi to heavy metals can differ between species and strains (Baldrian 2003; Fomina et al. 2007). Fungi that produce sterile mycelium (no spores) would have little impact on air quality and also represent another avenue for a greener production alternative. Lenhard (1956) introduced the concept of determining the metabolic activity of microorganisms in soil and other habitats by measuring dehydrogenase activity. Enzymes are the direct mediators for biological catabolism of soil organic and mineral components. These catalysts provide a meaningful assessment of reaction rates for important soil processes. In addition, soil enzyme activities can be helpful in measuring the microbial activity, soil productivity and inhibiting activity of soil pollutants (Tate 1995). Silver nanoparticles have been well known for their inhibitory and antimicrobial effects. It is also noteworthy that the presence of silver ions enhances biochemical processes in entities, such as soil, plant, etc. The present investigation is taken up for the synthesis of silver nanoparticles using the secrets of indigenous fungal species isolated from barite mine contaminated soils (collected from Mangampeta barite mining area of YSR Kadapa District, Andhra Pradesh, India) and to assess the impact of these silver nanoparticles on soil exo-enzymatic activity in the same soils. To the best of our knowledge, this is the first report on this kind of work in barite mine contaminated soils.

\section{Materials and methods}

Production of mycogenic AgNPs (m-AgNPs)

The soil samples from barite mines (Mangampeta, YSR Kadapa District, AP, India) were collected and serially diluted and inoculated on to potato dextrose agar (PDA) media for identification of species. Among the various fungal species Fusarium solani ( $F$. solani) mycelia were found as major strain. The $F$. solani strains were confirmed by morphological, biochemical, and microscopic examination of spores before experimentation. The $F$. solani isolates were grown freshly by inoculating on to sterile PDA medium separately and the flasks were incubated at $28{ }^{\circ} \mathrm{C}$ and $2,000 \mathrm{rpm}$ at $\mathrm{pH} 7.2$ for $96 \mathrm{~h}$. After the $96 \mathrm{~h}$ of incubation, the cultures containing dense quantity of mycelium were selected and used for synthesis. The cultures were centrifuged at 4,000 rpm for $30 \mathrm{~min}$ and the supernatant was used for the biosynthesis of AgNPs. De-ionized water was used as solvent for the biological synthesis of AgNPs. The supernatant of $F$. solani was collected and added separately as $1 \%(\mathrm{v} / \mathrm{v})$ to the reaction vessel containing silver nitrate $(1 \mathrm{mM}$ concentration) and incubated on an orbital shaker under dark conditions for $96 \mathrm{~h}$ at $30^{\circ} \mathrm{C}$ (Logeswari et al. 2012). Silver nanoparticles were biologically synthesized by the culture supernatant of $F$. solani. A $10 \mathrm{ml}$ of filtered (Whatman no. 1 filter paper) supernatant of $F$. solani was added to the $90 \mathrm{ml}$ of $1 \mathrm{mM} \mathrm{AgNO}$ solution and kept at room temperature for $24 \mathrm{~h}$.

UV-visible spectral analysis

The absorption spectrum, eventually the localized surface plasmon resonance (LSPR) of the m-AgNPs was recorded using a UV-visible spectrophotometer (Shimadzu, UV2450, double beam). A small aliquot analysis was done using UV-Vis spectrophotometer.

\section{FT-IR analysis}

The biosynthesized silver nanoparticles were mixed with potassium bromide powder to form a pellet. The pellet was further analyzed using the Fourier transform infrared spectrophotometer (FT-IR) using the diffuse reflectance mode (BRUKER-Tensor 27).

Dynamic light scattering (particle size) and zeta potential analysis

Dynamic light scattering (DLS) technique is one of the widely accepted techniques to measure the size of the particles in a hydrosol. The particle size measurements were carried out using nanopartica SZ-100 (HORIBA). Zeta potential also measured using electrical conducting cell.

High-resolution transmission electron microscopy (HRTEM)

The sample was characterized by Transmission Electron Microscopy (JEOL 3010; USA) and the sample for transmission electron microscopy (TEM) analysis was prepared by drop casting the nanoparticles suspension on the carbon coated $\mathrm{Cu}$ grids. 
Inductively coupled plasma optical emission spectroscopy (ICP-OES)

Heavy metals present in soil sample was determined by digesting the filtered soil solution with $10 \mathrm{ml}$ of digestion mixture $\left(\left[\mathrm{HNO}_{3}\right]+[\mathrm{HCl}]\right.$ in 3:1 ratio). The mixture was heated at $90-95{ }^{\circ} \mathrm{C}$ until complete digestion. It was then filtered and transferred into a standard flask and the volume was made up to the mark with $1 \% \mathrm{HNO}_{3}$. The sample was analyzed using ICP-OES for the estimation of the heavy metals concentration.

Preparation of soil samples with $F$. solani cultures

The test unit was prepared using plastic cups with $30 \mathrm{~g}$ of sterile soil. The AgNPs concentrations of 10, 50, 100, $150 \mathrm{ppm}$ were prepared. The soil sample was incubated with $F$. solani for $0-30$ days at $28{ }^{\circ} \mathrm{C}$ and different concentrations of m-AgNPs $(10,50,100,150 \mathrm{ppm})$ were added. The moisture content was adjusted to about $60 \%$ of the water holding capacity (WHC), with the soils then incubated at room temperature for $0,24 \mathrm{~h}, 7$ and 30 days. The soil $\mathrm{pH}$ (6.4) was measured for each exposure concentration and duration, but no significant differences were observed.

\section{Assay of the soil exo-enzymatic activities}

Biochemical analyses of soil involved determinations of the activity of soil dehydrogenases (SDH) with TTC $(2,3,5-$ triphenyltetrazolium chloride) as substrate (Öhlinger 1996), the activity of urease enzyme (URE, EC 3.5.1.5) determined according to Alef and Nannipieri (1998), and activities of acid phosphatase (ACP, EC 3.1.3.1) and alkaline phosphatase (ALP, EC 3.1.3.2) measured according to the method described by Alef and Nannipieri (1998). $\beta$-Glucosidase (EC 3.2.1.21) activity was determined according to Eivazi and Tabatabai (1988). The assay was performed by spectrophotometric measurement of $p$-nitrophenyl ( $p$-NP) released after $1 \mathrm{~h}$ incubation of soil samples with $p$-nitrophenyl- $\beta$-D-glucopyranoside ( $p$ NPG) at $37{ }^{\circ} \mathrm{C}$ in modified universal buffer ( $\mathrm{pH}$ 6.0) as the substrate. The enzyme activity was expressed as $\mathrm{mM}$ of $p$-NP released $\mathrm{kg}^{-1}$ dry soil $\mathrm{h}^{-1}\left(\mathrm{mM} p-\mathrm{NP} \mathrm{kg}^{-1} \mathrm{~h}^{-1}\right)$.

\section{Results and discussion}

Microbial synthesis of AgNPs (m-AgNPs)

The appearance and color change of solution from yellow to brown in the silver nitrate-treated flask containing $F$. solani culture filtrate indicates the formation of silver

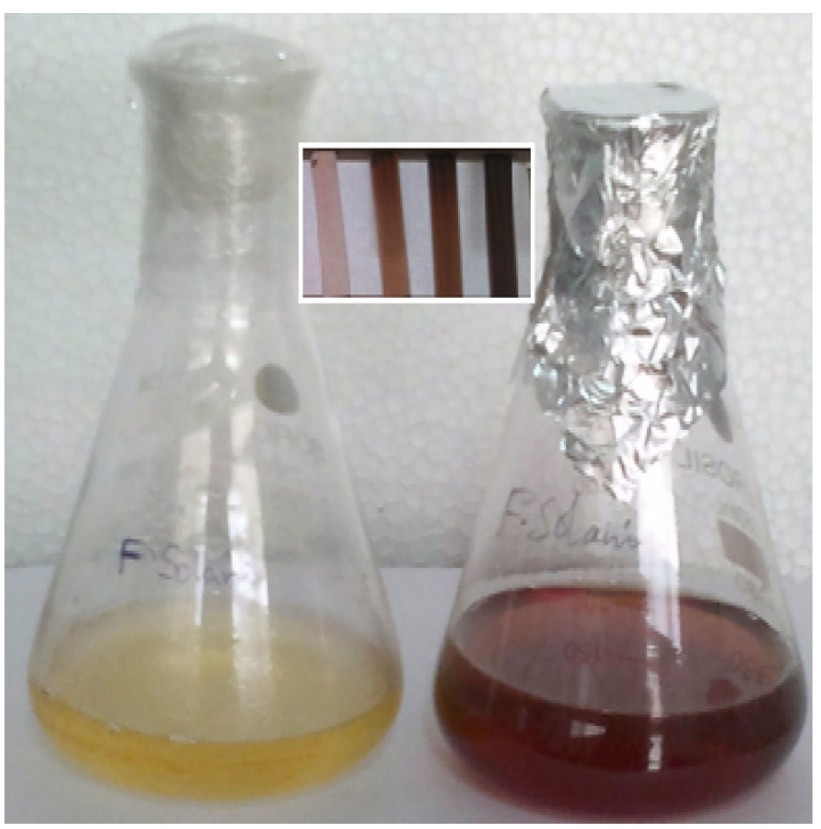

Fig. 1 Change of colour of broth of $F$. solani before (a) and after (b) addition of silver nitrate (change of colour is due to the localized surface plasmon resonance and confirms the formation of silver nanoparticles)

nanoparticles, whereas, no color change was observed in the culture supernatant without silver nitrate. Figure 1 shows Erlenmeyer flasks containing the cell-free filtrate of $F$. solani alone (a) and $F$. solani mixed with silver nitrate (b) after completion of reaction for $24 \mathrm{~h}$ of duration. Earlier reports evidenced that nitrates can induce nitrate reductase, while ammonium and glutamine inhibit the same enzyme can cause nitrate repression in fungi (DunnColeman et al. 1984; Premakumar et al. 1979). If nitrate reductase is the sole responsible enzyme for AgNPs synthesis, then repression of the enzyme would either inhibit NPs formation or cause NPs formation by another pathway. The mechanism of the biosynthesized nanoparticles involves the reduction of silver ions by the electron shuttle through enzymatic metal reduction process. Earlier reports revealed that $\mathrm{NADH}$ and $\mathrm{NADH}-$ dependent enzymes are vital in the biosynthesis of metal nanoparticles (Kalimuthu et al. 2008). The microbes are well known to secrete the cofactors NADH and NADH-dependent enzymes, such as nitrate reductase might be responsible for the bioreduction of metal ions and the subsequent formation of silver nanoparticles (Logeswari et al. 2012).

UV-Vis spectral studies: recording localized surface plasmon resonance of $\mathrm{m}$-AgNPs

UV-Vis spectroscopy is one of the most widely used techniques for structural characterization of AgNPs. The color change was observed from yellow to brown due to 


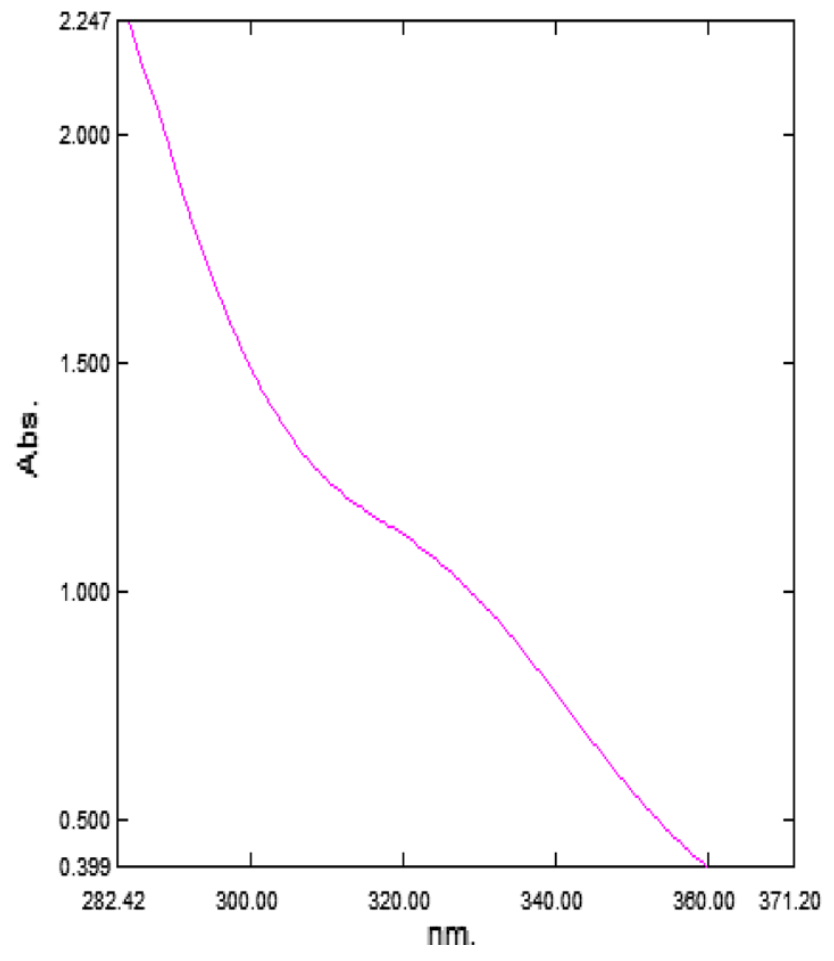

Fig. 2 UV-visible absorption spectra showing localized surface plasmon resonance (LSPR) of silver nanoparticles synthesized using F. solani at $330 \mathrm{~nm}$

the bioreduction of the $\mathrm{Ag}^{+}$ions in the flask containing silver nitrate and fungal secrets. The extracellular components of the $F$. solani culture reduced the $\mathrm{Ag}^{+}$ions in the medium. The absorption spectra of nanoparticles showed highly symmetric single-band absorption with peak maximum at $330 \mathrm{~nm}$ (Fig. 2). The intensity of the biosynthesized AgNPs showed increased absorbance and broad peak observed at $330 \mathrm{~nm}$, corresponds to the surface plasmon resonance (SPR) of the silver nanoparticles. The broad spectrum clearly indicates the polydispersity of the formed AgNPs which is also confirmed with the TEM micrographs.

\section{FT-IR analysis}

The FT-IR spectrum was recorded from the potassium iodide pellet with the biosynthesized silver nanoparticles formed after $24 \mathrm{~h}$ of incubation with $F$. solani. Figure 3 shows the amide linkages between the amino acid residues in proteins giving rise to the well-known signatures in the infrared region of the electromagnetic spectrum. The bands observed at $3,343 \mathrm{~cm}^{-1}$, which fall near $3,280 \mathrm{~cm}^{-1}$, were assigned to the stretching vibrations of the primary amines, while the corresponding bending vibrations were seen at $1,635 \mathrm{~cm}^{-1}$. The two small bands observed at 1,312 and $1,138 \mathrm{~cm}^{-1}$ represent the $\mathrm{C}-\mathrm{N}$ stretching vibrations of aromatic and aliphatic amines, respectively. The bands observed in the FT-IR of the biosynthesized AgNPs using $F$. solani confirm the presence of proteins. The proteins present in the culture sample are able to bind nanoparticles either through free amine groups or cysteine residues in the proteins (Mandal et al. 2005) through electrostatic attraction of negatively charged carboxylate groups (Sastry et al. $2003)$ present in the enzyme produced by $F$. solani. The formation and stability of the biosynthesized AgNPs by proteins is a possibility (Sastry et al. 2003).

\section{High-resolution transmission electron microscopy}

The sample was characterized by Transmission Electron Microscopy (JEOL 3010; USA) and the sample for TEM analysis was prepared by drop casting the nanoparticles
Fig. 3 Fourier transform infrared spectra (FT-IR) micrograph showing the functional groups involved in the reduction and stabilization of silver nanoparticles synthesized using $F$. solani

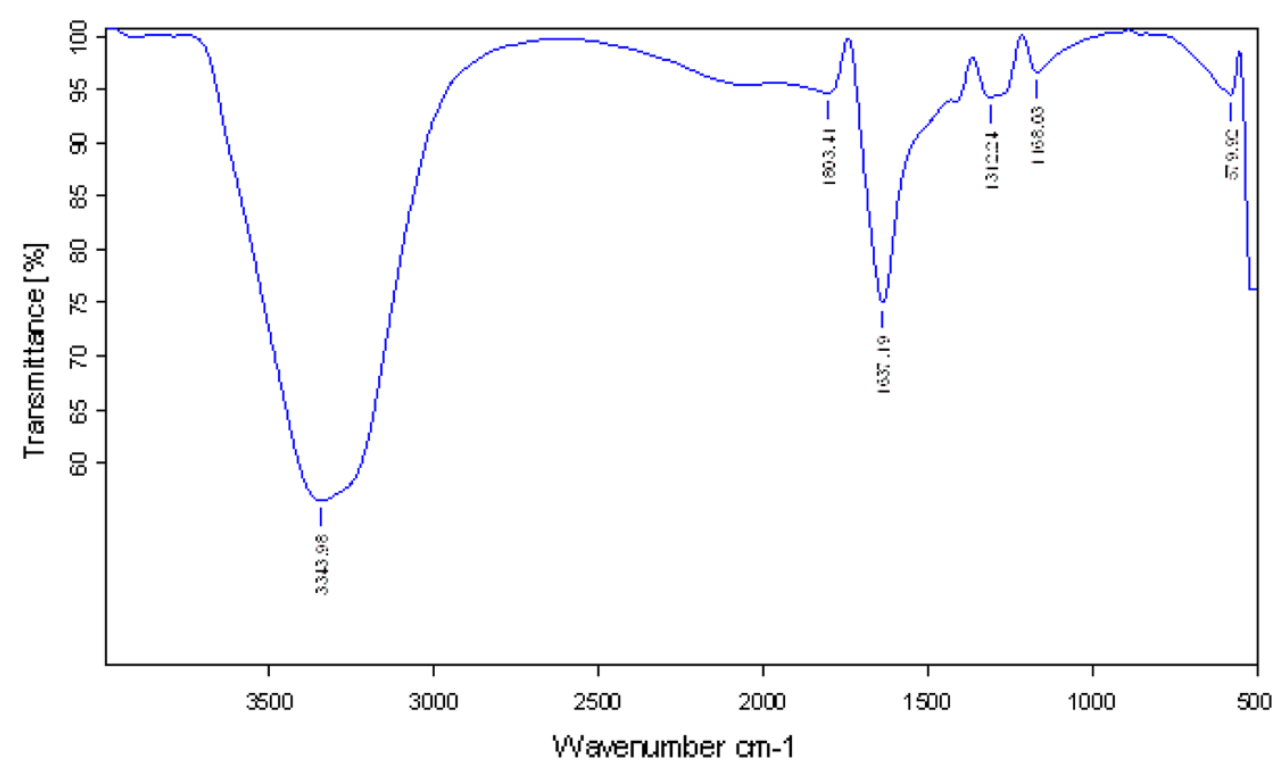



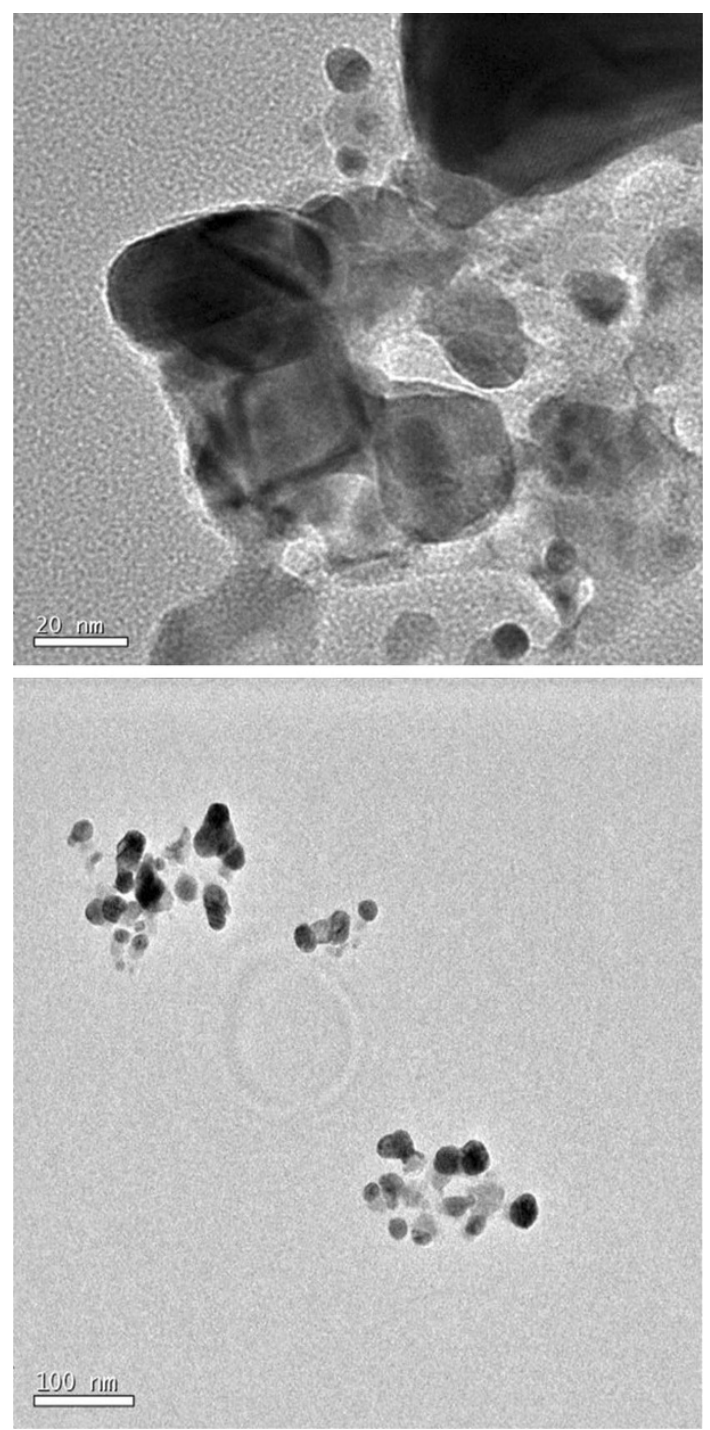

Fig. 4 Transmission electron microscopic (TEM) micrographs showing the silver nanoparticles synthesized using $F$. solani

suspension on the carbon coated $\mathrm{Cu}$ grids. The TEM micrographs show polydispersed (Fig. 4) relatively spherical AgNPs with an average size of $80 \mathrm{~nm}$.

Dynamic light scattering and zeta potential measurements

The hydrodynamic diameter of the hydrosol measured using DLS technique also confirmed the size of the AgNPs as $87.2 \mathrm{~nm}$ (Figs. 5, 6) which is in good agreement with the TEM studies. The electrophoretic mobility ($0.000164 \mathrm{~cm}^{2} / \mathrm{Vs}$ ) coupled with negative zeta potential $(21.1 \mathrm{mV})$ indicates the formed AgNPs are highly stable and receives greater repulsion in soil matrix since most of the soil colloids are negatively charged.
The ICP-OES analysis of the soils was done to reveal the quantitative presence of heavy metals (Table 1) in the barite mine contaminated soils. It is evident that a variety of heavy metals like, $\mathrm{Pb}, \mathrm{Zn}, \mathrm{As}, \mathrm{Cd}$, etc., were present with different concentrations which have great significance in containing soil biochemical processes.

\section{Effect of mycogenic AgNPs on soil exo-enzymes}

Soil enzyme activities have the potential to provide a unique integrative and reliable biological assessment of soils because of their relationship to soil biology and rapid response to changes in soil organic matter (SOM) and soil management (Dick 1994; Lulu and Insam 2000). Soil enzymatic activities have been used to ascertain different issues of environmental qualities (Table 2). The effect of m-AgNPs on the soil exo enzyme activities in barite mine contaminated soils were discussed (Figs. 7a, b, 8, 9, 10).

\section{Phosphatases}

In soil ecosystems, phosphatases are believed to play vital role in P-cycling (Speir and Ross 1978) as they are correlated to $\mathrm{P}$ stress and plant growth. Apart from being good indicators of soil fertility, phosphatase also plays a key role in the maintenance of soil system (Eivazi and Tabatabai 1977; Dick et al. 2000). The assay performed on ALP and ACP activities of soil with the application of m-AgNPs are depicted in Fig. 7a and b. It is evident from the results that enzymatic activity at zeroth day increased in all the treatments except for $50 \mathrm{ppm}$. However, inhibition of the activity was observed at first day, but on tenth day and 30 days of incubation at all the higher concentrations of AgNPs (50, 100, $150 \mathrm{ppm})$ the enzymatic activity increased. It has been reported in the literature that adsorption by SOM reduces the mobility of engineered nanoparticles (ENPs) in the soil matrix is curtailed and hence their influence on the microbial populations is drastically reduced. ENPs can be strongly sorbed to soil surfaces and SOM making them less mobile or are small enough to be trapped in the inter-spaces of soil particles and might therefore travel farther than larger particles before becoming trapped in the soil matrix. The strength of sorption would, however, depend on the size, chemistry, aggregation behavior, conditions under which it is applied, etc. In fact, whether an ENP can be hazardous in soil depends not only on its concentration, but also on the likelihood of it ever coming into contact with microbial cells. It may also be noted that natural colloids and ENPs in the environment can interact with one another and also with other larger particles (Simonet and Valcárcel 2009). Studies also demonstrate lack of toxicity from bulk

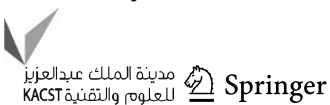


Fig. 5 Particle size distribution (measured using dynamic light scattering technique) of m-AgNPs synthesized using $F$. solani

Fig. 6 Zeta potential of m-AgNPs synthesized using $F$. solani

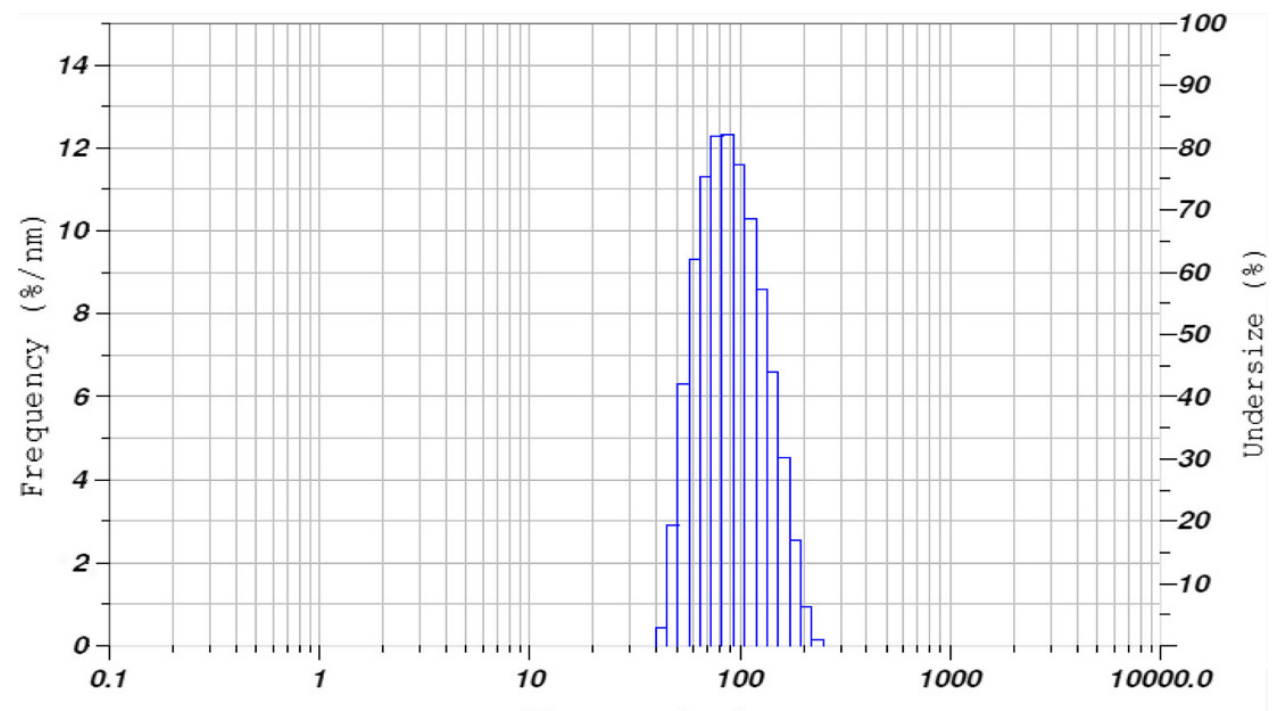

Diameter $(\mathrm{nm})$

Calculation Results

\begin{tabular}{|c|c|c|c|c|}
\hline Peak No. & S.P.Area Ratlo & Mean & S. D. & Mode \\
\hline 1 & 1.00 & $95.9 \mathrm{~nm}$ & $34.8 \mathrm{~nm}$ & $87.2 \mathrm{~nm}$ \\
\hline 2 & -- & $--\mathrm{nm}$ & $\cdots-\mathrm{nm}$ & $\cdots-\cdots \mathrm{nm}$ \\
\hline 3 & $-\cdots$ & $--\mathrm{nm}$ & $\cdots-\mathrm{nm}$ & $\cdots-\mathrm{nm}$ \\
\hline Total & 1.00 & $95.9 \mathrm{~nm}$ & $34.8 \mathrm{~nm}$ & $87.2 \mathrm{~nm}$ \\
\hline
\end{tabular}
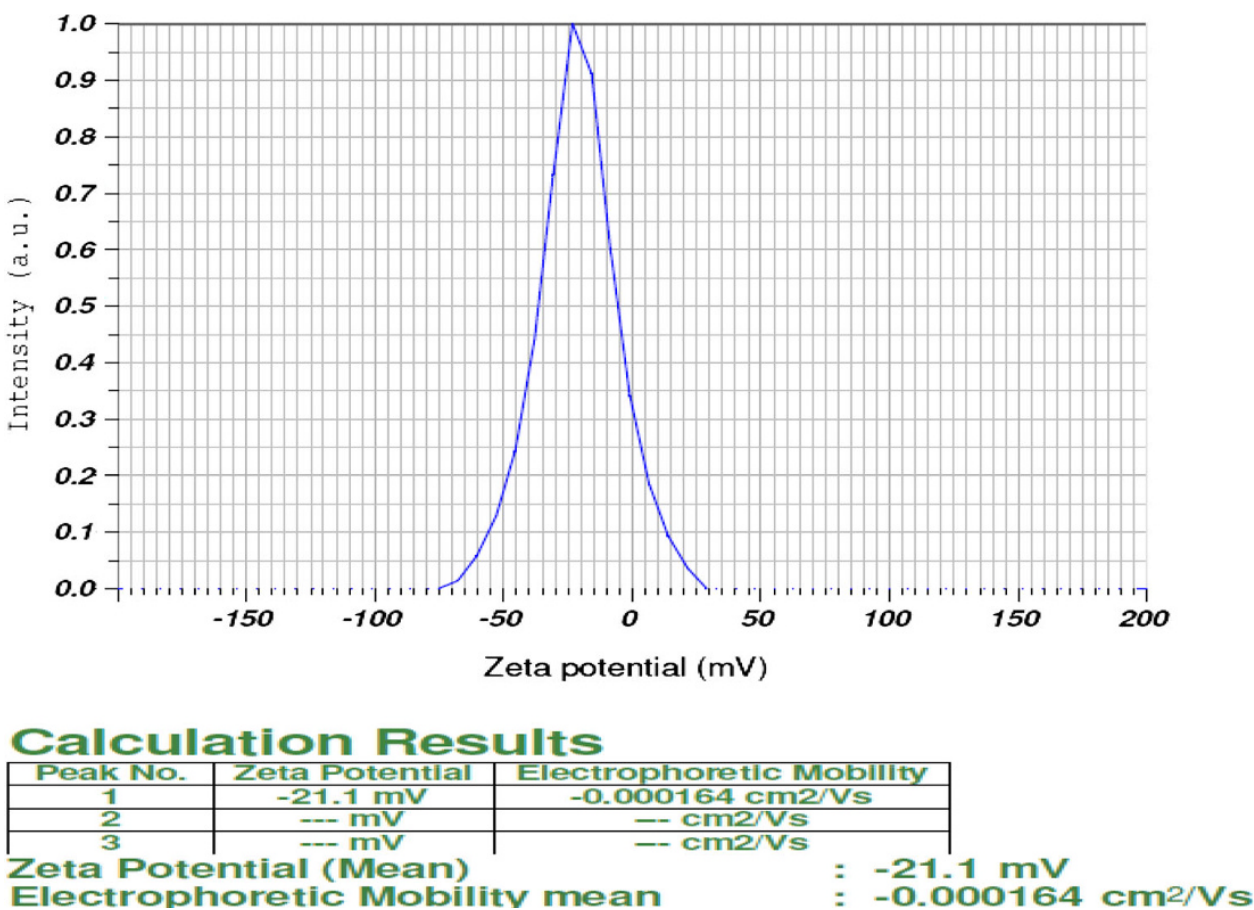

materials (300 nm) of Ag-, CuO- and $\mathrm{ZnO}-\mathrm{NP}$ (Gajjar et al. 2009), suggesting that aggregation of the ENPs into larger particles, possibly by factors present in the soil (natural colloids, SOM, etc.) may reduce their antimicrobial activity.
$\beta$-Glucosidase

$\beta$-Glucosidase is a common and predominant enzyme in soils (Eivazi and Tabatabai 1988; Tabatabai 1994a, b). $\beta$ Glucosidase is characteristically useful as a soil quality 
Table 1 The concentration of heavy metals present in the baryte mine contaminated soils estimated using the inductively coupled plasma-optical emission spectrophotometer (ICP-OES)

\begin{tabular}{llc}
\hline S. no. & Element & Metal ion concentration $(\mathrm{ppm})$ \\
\hline 1. & $\mathrm{As}$ & $0.6488 \pm 0.09$ \\
2. & $\mathrm{Ca}$ & $9.8372 \pm 0.05$ \\
3. & $\mathrm{Cd}$ & $0.1274 \pm 0.08$ \\
4. & $\mathrm{Cr}$ & $0.7317 \pm 0.04$ \\
5. & $\mathrm{Cu}$ & $0.8773 \pm 0.06$ \\
6. & $\mathrm{Fe}$ & $163.365 \pm 2.54$ \\
7. & $\mathrm{Hg}$ & $0.3630 \pm 0.02$ \\
8. & $\mathrm{~K}$ & $41.3029 \pm 1.8$ \\
9. & $\mathrm{Mg}$ & $28.1182 \pm 1.2$ \\
10. & $\mathrm{Mn}$ & $0.4477 \pm 0.04$ \\
11. & $\mathrm{Mo}$ & $0.4039 \pm 0.05$ \\
12. & $\mathrm{Na}$ & $2.6413 \pm 0.3$ \\
13. & $\mathrm{P}$ & $1.0193 \pm 0.07$ \\
14. & $\mathrm{~Pb}$ & $0.4850 \pm 0.06$ \\
15. & $\mathrm{Se}$ & $0.5300 \pm 0.02$ \\
16. & $\mathrm{Ni}$ & $0.8162 \pm 0.1$ \\
17. & $\mathrm{Zn}$ & $1.4555 \pm 0.8$ \\
18. & $\mathrm{~B}$ & $0.4703 \pm 0.09$ \\
\hline
\end{tabular}

The values presented are the \pm SE of three replicates

Table 2 Important soil exo-enzymes as indicators of soil biochemical processes (Das and Varma 2011)

\begin{tabular}{llll}
\hline $\begin{array}{l}\text { S. } \\
\text { no. }\end{array}$ enzyme of the & $\begin{array}{l}\text { Enzyme } \\
\text { reaction }\end{array}$ & $\begin{array}{l}\text { Indicator of microbial } \\
\text { activity/biochemical process }\end{array}$ \\
\hline 1. & Dehydrogenase & $\begin{array}{c}\text { Electron } \\
\text { transport } \\
\text { system }\end{array}$ & C-cycling \\
2. $\quad$ B-Glucosidase & $\begin{array}{c}\text { Cellobiose } \\
\text { hydrolysis }\end{array}$ & C-cycling \\
3. Urease & $\begin{array}{c}\text { Urea } \\
\text { hydrolysis } \\
\text { Release of } \\
\text { PO }_{4}^{-}\end{array}$ & P-cycling \\
4. Phosphatase & $\begin{array}{c}\text { Hydrolysis } \\
\text { 5. Soil enzymes }\end{array}$ & $\begin{array}{l}\text { General organic matter } \\
\text { Degradative enzyme activities }\end{array}$ \\
\hline
\end{tabular}

indicator, and largely reflects past biological activity, the capacity of soil to stabilize the SOM, and can be used to detect management effect on soils (Bandick and Dick 1999; Ndiaye et al. 2000). From Fig. 8, it is clear that enzymatic activity decreased in all the treatments at zeroth day as it is needed to disruption of the cell. However, from first day to 30 days the assay indicates the increased glucosidase activity in all treatments but relatively recorded low values at higher concentrations of AgNPs (100, $150 \mathrm{ppm}$ ) (Fig. 8). This enzyme has a strong relationship with the microbial biomass that suggests that the activity of
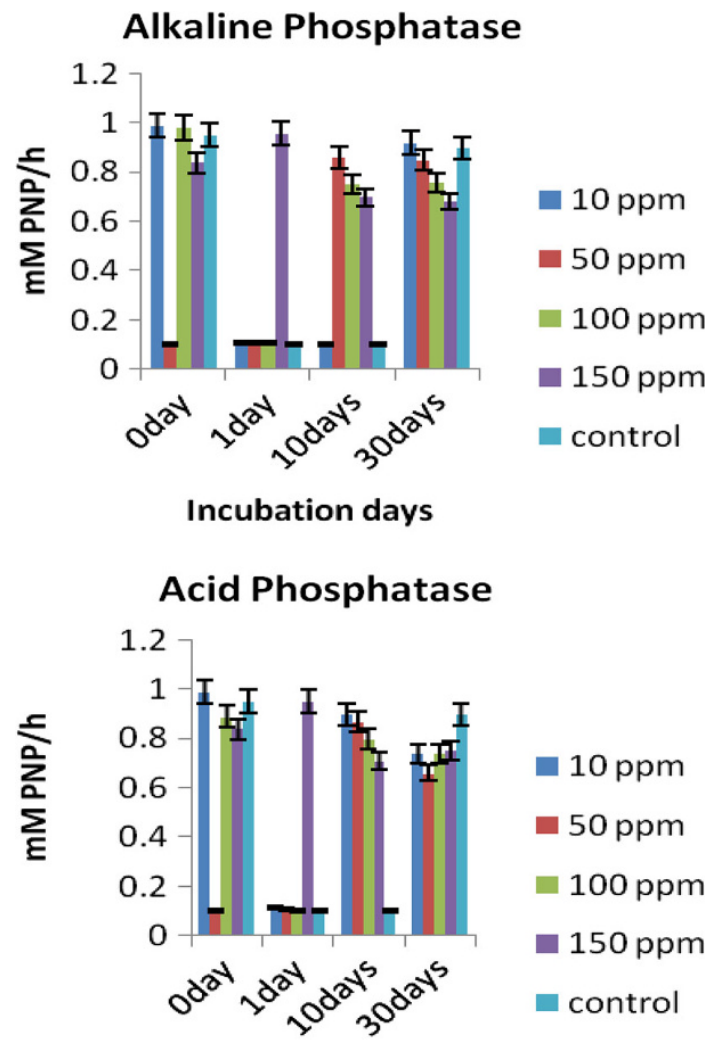

Incubation days

Fig. 7 Effect of m-AgNPs on alkaline phosphatase (ALP) and acid phosphatase (ACP) enzyme activities during 0-30 days of incubation in baryte mine contaminates soils

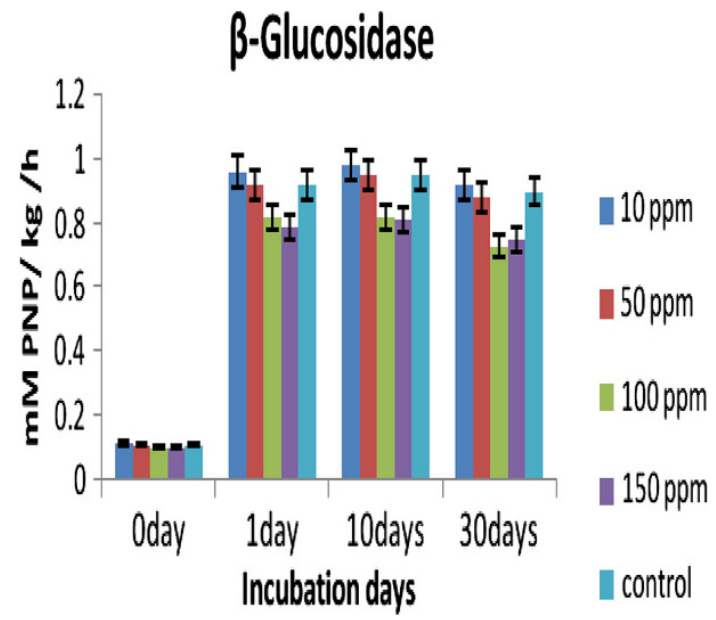

Fig. 8 Effect of $m$-AgNPs on $\beta$-glucosidase activity during 0-30 days of incubation in baryte mine contaminated soils

extracellular immobilized enzymes is negligible. However, several studies show a strong relationship between $\beta$-glucosidase activity and clay content which may reflect the potential for enzyme immobilization in the soil. Therefore, AgNPs at lower concentrations promotes the $\beta$-glucosidase activity in the soils. 


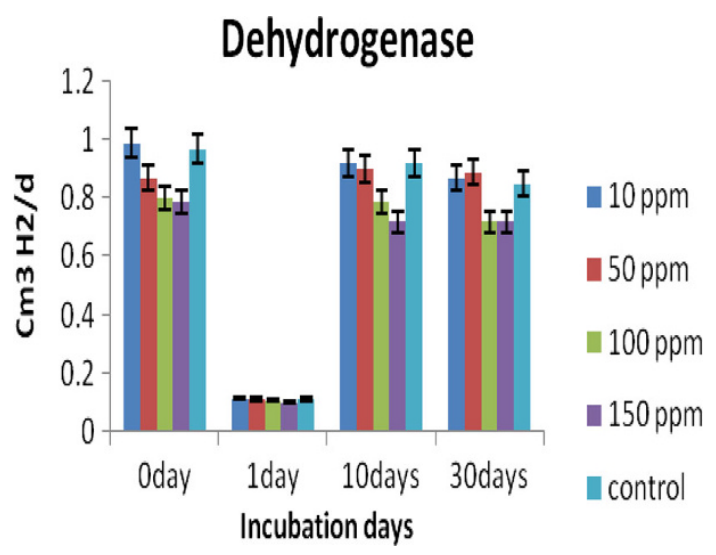

Fig. 9 Effect of m-AgNPs on dehydrogenase activity during 0-30 days of incubation in baryte mine contaminated soils

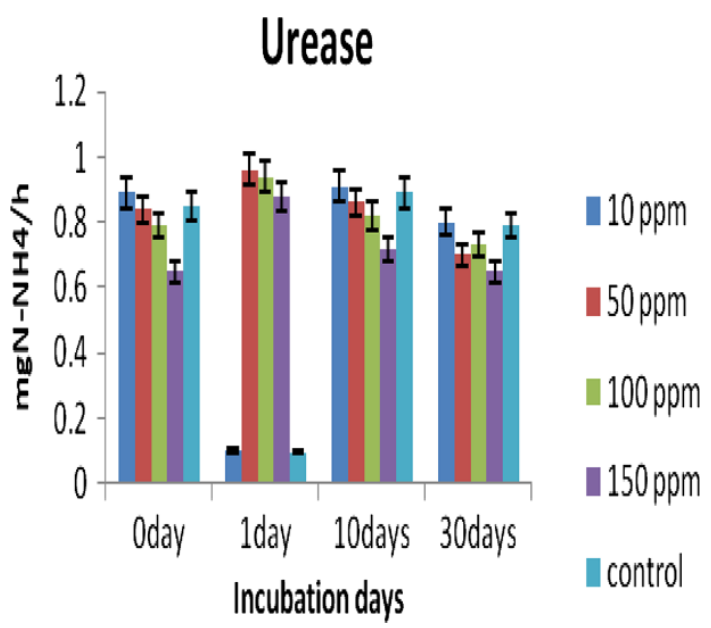

Fig. 10 Effect of m-AgNPs on soil urease activity during 0-30 days of incubation in baryte mine contaminated soils

\section{Dehydrogenase}

The dehydrogenase enzyme activity is also commonly used as an indicator of biological activity in soils (Burns 1978) to support biochemical processes that are essential to maintain soil fertility as well as soil health. This enzyme exists as an integral part of intact cells but does not accumulate extracellularly in the soil. Dehydrogenase enzyme is known to oxidize SOM by transferring protons and electrons from substrates to acceptors. Metal nanoparticles, such as Ag have been proven to be toxic to soil micro biota several researchers demonstrated the toxic effect of $\mathrm{Ag}$ on soil dehydrogenase activity as severe and bacterial colony growth was inhibited at levels between 0.1 and $0.5 \mathrm{mg} \mathrm{Ag} \mathrm{kg}{ }^{-1}$ soil. These finding also suggests that soil denitrifying bacteria are susceptible to inhibition by Ag. The effect of Ag was found that only
$20 \%$ due to denitrifying bacteria as compared to control remained in samples with the highest $\mathrm{Ag}$ concentration. Further during 14, 30 and 90 days of incubation, the inhibition patterns were similar, and no recovery was observed. In the present investigation, the mycogenic AgNPs showed similar inhibition activity up to $24 \mathrm{~h}$, but after 1 up to 30 days inhibition activity decreased at all the concentrations but the recorded activity is less as compared to control and recovery of the activity was observed (Fig. 9). The surface of the $\mathrm{m}$-AgNPs is coated with the secrets of $F$. solani which are organic in nature is the causative for the recovery of the activity over a period of time.

\section{Urease}

Urease enzyme is responsible for the hydrolysis of urea fertilizers applied to the soil into $\mathrm{NH}_{3}$ and $\mathrm{CO}_{2}$ with the concomitant rise in soil pH (Andrews et al. 1989; Byrnes and Amberger 1989). Urease activity in soils is influenced by many factors, which include cropping history, SOM, soil depth, soil amendments, heavy metals, and environmental factors, such as temperatures (Tabatabai 1977; Yang et al. 2006). For example, studies have shown that urease was very sensitive to toxic concentrations of heavy metals (Yang et al. 2006). It is evident from Fig. 10 that urease activity is low in control and at $10 \mathrm{ppm}$ of m-AgNPs during day 1 and increased up to 10 days and almost similar up to 30 days. This indicates that $\mathrm{m}-\mathrm{AgNPs}$ affects the N-cycling instantly, but has no significant affect over a period of time (30 days).

\section{Conclusion}

The fungi $F$. solani isolated from barytes mine contaminated soil was a potential candidate for the synthesis of AgNPs. On application, m-AgNPs were effective in improving soil quality and oxidising ability of SOM as assessed through the enzymatic processes, but there is no pattern observed though concentration dependent activity was recorded (10-150 ppm). As the properties of the NPs largely dependent on the genesis, surface coating and size the results obtained in the present study may not be extrapolated to other nanomaterial or any other soils contaminated with different pollutants. Thus, the effects of $\mathrm{m}$-AgNPs on soil exo-enzymatic activity may be useful to reduce the concentration of the heavy metals leads to in situ bioremediation of contaminated soils.

Open Access This article is distributed under the terms of the Creative Commons Attribution License which permits any use, distribution, and reproduction in any medium, provided the original author(s) and the source are credited. 


\section{References}

Abou ElNour MM, Eftaiha A, AlWarthan A, Ammar RAA (2010) Synthesis and application of silver nanoparticles. Arab J Chem 3:135-140

Alef K, Nannipieri P (1998) Urease activity. In: Alef K, Nannipieri P (eds) Methods in applied soil microbiology and biochemistry. Academic Press, Harcourt Brace and Company, London, pp 316-320

Andrews RK, Blakeley RL, Zerner B (1989) Urease: a Ni(II) metalloenzyme. In: Lancaster JR (ed) The bioinorganic chemistry of nickel. VCH, New York, pp 141-166. doi:10.1016/j. colsurfb.2010.07.036

Baldrian P (2003) Interactions of heavy metals with white rot fungi. Enzyme Microbial Technol 32:78-91

Bandick AK, Dick RP (1999) Field management effects on soil enzyme activities. Soil Biol Biochem 31:1471-1479

Burns RG (1978) Enzyme activity in soil: some theoretical and practical considerations. In: Bums RG (ed) Soil enzymes. Academic, London, pp 295-340

Byrnes BH, Amberger A (1989) Fate of broadcast urea in a flooded soil when treated with $N$-(n-butyl) thiophosphoric triamide, a urease inhibitor. Fertil Res 18:221-231

Das SK, Varma A (2011) Role of enzymes in maintaining soil health. In: Shukla G, Varma A (eds) Soil enzymology, soil biology, chap 22. Springer, Berlin, pp 25-42. doi:10.1007/978-3-64214225-3_2

Dhoondia ZH, Chakraborty H (2012) Lactobacillus mediated synthesis of silver oxide nanoparticles. In: Prete P (ed) Nanomaterials and nanotechnology, vol 2. InTech. ISBN: 1847-9804, doi:10. 5772/55741. http://www.intechopen.com/journals/nanomaterials

Dick RP (1994) Soil enzyme activities as indicators of soil quality. In: Doran JW, Coleman DC, Bezdicek DF, Stewart BA (eds) Soil enzymes. Soil Science Society of America Madison, Doran, pp 107-124

Dick WA, Cheng L, Wang P (2000) Soil acid and alkaline phosphatase activity as $\mathrm{pH}$ adjustment indicators. Soil Biol Biochem 32:1915-1919

Dunn-Coleman SN, Smarrell J, Garrett RH (1984) Nitrate assimilation in eukaryotic cells. Int Rev Cytol 92:1-50

Durán N, Marcato PD, Alves OL, de Souza IHG, Esposito E (2005) Mechanistic aspects of biosynthesis of silver nanoparticles by several Fusarium oxysporum strains. J Nanotechnol 3:1-7

Eivazi F, Tabatabai MA (1977) Phosphates in soils. Soil Biol Biochem 9:167-172

Eivazi F, Tabatabai MA (1988) Glucosidases and galactosidases in soils. Soil Biol Biochem 20:601-606

Fomina M, Charnock J, Bowen AD, Gadd GM (2007) X-ray absorption spectroscopy (XAS) of toxic metal mineral transformations by fungi. Environ Microbiol 9:308-321

Gajjar P, Pettee B, Britt DW, Huang W, Johnson WP, Anderson AJ (2009) Antimicrobial activities of commercial nanoparticles against an environmental soil microbe, Pseudomonas putida KT2440. J Biol Eng 3:1-13

Ghorbani HR, Safekordi AA, Attar H, Rezayat Sorkhabadi SM (2011) Biological and non-biological methods for silver nanoparticles synthesis. Chem Biochem Eng Q 25:317-326

Kalimuthu K, Babu RS, Venkataraman D, Bilal M, Gurunathan S (2008) Biosynthesis of silver nanocrystals by Bacillus licheniformis. Colloids Surf B Biointerfaces 65:150-153. doi:10.1016/j. colsurfb.2008.02.018
Lenhard G (1956) The dehydrogenase activity in soil as a measure of the activity of soil microorganisms. Z Pflanzenernaehr Dueng Bodenkd 73:1-11

Logeswari P, Silambarasan S, Abraham J (2012) Synthesis of silver nanoparticles using plants extract and analysis of their antimicrobial property. J Saudi Chem Soc. doi:10.1016/j.jscs.2012.04. 007

Lulu B, Insam H (2000) Medium-term effects of a single application of mustard residues on soil microbiota and $\mathrm{C}$ content of vertisols. Biol Fertil Soils 31:108-113

Mandal S, Phadtare S, Sastry M (2005) Interfacing biology with nanoparticles. Curr Appl Phys 5:118-127

Mohanpuria P, Rana NK, Yadav SK (2008) Biosynthesis of nanoparticles: technological concepts and future applications. J Nanoparticle Res 10:507-517

Naveen H, Kumar G, Karthik L, Roa B (2010) Extracellular biosynthesis of silver nanoparticles using the filamentous fungus Penicillium sp. Arch Appl Sci Res 2:161-167

Ndiaye EL, Sandeno JM, McGrath D, Dick RP (2000) Integrative biological indicators for detecting change in soil quality. Am J Altern Agric 15:26-36

Öhlinger R (1996) Dehydrogenase activity with the substrate TTC. In: Schinner F, Öhlinger R, Kandeler E, Margesin R (eds) Methods in soil biology. Springer, Berlin, pp 241-243

Popescu M, Velea A, Lőrinczi A (2010) Biogenic production of nanoparticles. Dig J Nanomater Biostruct 5:1035-1040

Prasad TNVKV, Elumalai EK (2011) Biofabrication of Ag nanoparticles using Moringa oleifera leaf extract and their antimicrobial activity. Asian Pac J Trop Biomed 1:439-442

Premakumar R, Sorger GJ, Gooden D (1979) Nitrogen metabolite repression of nitrate reductase in Neurospora crassa. J Bacteriol 137:1119-1126

Sastry M, Ahmad A, Khan MI, Kumar R (2003) Biosynthesis of metal nanoparticles using fungi and actinomycete. Curr Sci $85: 162-170$

Simonet BM, Valcárcel M (2009) Monitoring nanoparticles in the environment. Anal Bioanal Chem 393:17-21

Speir TW, Ross DJ (1978) Soil phosphatase and sulphatase. In: Burns RG (ed) Soil enzymes. Academic, London, pp 197-250

Tabatabai MA (1977) Effects of trace elements on urease activity in soils. Soil Biol Biochem 9:9-13

Tabatabai MA (1994a) Soil enzymes. In: Weaver RW, Angle JS, Bottomley PS (eds) Methods of soil analysis, part 2. Microbiological and biochemical properties. Soil Science Society of America, Madison, pp 775-833

Tabatabai MA (1994b) Soil enzymes. In: Mickelson SH (ed) Methods of soil analysis, Part 2. Microbiological and biochemical properties. Soil Science Society of America, Madison, pp 775-833

Tate RL (1995) Soil microbiology. Wiley, New York

Tuomela M, Steffen KT, Kerko E, Hartikainen H, Hofrichter M, Hatakka A (2005) Influence of Pb contamination in boreal forest soil on the growth and ligninolytic activity of litter-decomposing fungi. FEMS Microbiol Ecol 53:179-186

Vahabi K, Mansoori GA, Karimi S (2011) Biosynthesis of silver nanoparticles by fungus Trichoderma reesei: a route for large scale production of AgNPs. Insci J 1:65-79

Yang Z, Liu S, Zheng D, Feng S (2006) Effects of cadmium, zinc and lead on soil enzyme activities. J Environ Sci 18:1135-1141. doi:10.1016/j.cap.2004.06.006 